\title{
Da mulher de virtude à enfermeira puericultora
}

\author{
From virtuous woman to childcare nurse \\ De la mujer de virtud a la enfermera puericultora \\ Nídia Salgueiro*
}

\section{Resumo}

Contexto: As experiências de vida e profissionais levam a autora a questionar-se sobre quem eram as «parteiras» curiosas. Vistas como mulheres de virtude, de sabedoria ou pelo contrário com um perfil mais sombrio. Se a sua assistência ao parto e recém-nascido teria coabitado com o exercício de parteiras certificadas pela Junta de Saúde Pública e diplomadas pela Faculdade de Medicina da Universidade de Coimbra e Escolas Médico-Cirúrgicas de Lisboa e Porto.

Objectivos: Construir o perfil das «parteiras» curiosas a partir de testemunhos de informantes privilegiados; verificar se coexistem a assistência prestada por parteiras sem e com formação.

Metodologia: Estabelece três grandes períodos, convicta que se interpenetram e coexistem. Este artigo foca os períodos: $d a$ mulher de virtude/curiosa à enfermeira-puericultora, utilizando entrevistas semiestruturadas e recorrendo a legislação. Resultados: A análise da informação aponta para o perfil de mulheres de virtude, de sabedoria, apesar da pouca instrução e de não terem recebido formação formal, coexistindo com parteiras diplomadas.

Conclusão: O estudo confirma os pressupostos iniciais e abre várias perspetivas de investigação.

Palavras-chave: mulher de virtude/curiosa, parteira, enfermeira-puericultora.

\begin{abstract}
Context: Life and professional experiences have lead the author to question who the amateur «midwives» were. Were they seen as virtuous or wise women or, on the contrary, did they have a more sombre profile? Could their assistance in childbirth and with the newborn could have coexisted with the exercise of midwives certified by the Public Health Board and graduates of the School of Medicine of Coimbra University and the Medical and Surgical Schools of Lisbon and Porto?

Objectives: To construct the profile of the amateur «midwives» from testimonies by privileged informants, to verify whether there was co-existence in the assistance rendered by trained and untrained midwives.

Methodology: To establish three great periods, with the conviction that they overlapped and coexisted. This article focuses on the periods: from virtuous woman/amateur to childcare nurse, using semi-structured interviews and by consulting legislation.

Results: The analysis of the information points to the profile of virtuous and wise women, although they were not highly educated and had not received formal training, who coexisted with certified midwives.

Conclusion: The study confirms the initial assumptions and opens various research perspectives.
\end{abstract}

Keywords: virtuous woman/amateur, midwife, childcare nurse.

* Enfermeira. Professora aposentada da Escola Superior de Enfermagem de Coimbra, 3046 851, Coimbra, Portugal [salgueiro.nidia@gmail.com]. Morada para correspondência: Rua Ferreira Borges, 91, 4º, 3000-180, Coimbra.

\section{Resumen}

Contexto: las experiencias vitales y profesionales llevan a la autora a cuestionarse sobre quiénes eran las «matronas» curiosas. Estas eran vistas como mujeres de virtud, de sabiduría o, por el contrario, con un perfil más sombrío. Si su asistencia al parto y al recién nacido habría cohabitado con el ejercicio de matronas certificadas por la Junta de Salud Pública y diplomadas por la Facultad de Medicina de la Universidad de Coímbra y las Escuelas Médico-Quirúrgicas de Lisboa y Oporto. Objetivos: construir el perfil de las «matronas» curiosas a partir de testimonios de informantes privilegiados, y verificar si coexiste la asistencia prestada por matronas sin y con formación.

Metodología: establece tres grandes períodos, convencida de que se mezclan y coexisten. Este artículo se centra en los períodos: de la mujer de virtud/curiosa a la enfermerapuericultora y, para ello, utiliza entrevistas semiestruturadas y recurre a la legislación.

Resultados: el análisis de la información apunta hacia el perfil de las mujeres de virtud, de sabiduría, a pesar de la poca instrucción y de no haber recibido formación formal, coexistiendo con matronas diplomadas.

Conclusión: el estudio confirma los presupuestos iniciales y abre varias perspectivas de investigación.

Palabras clave: mujer de virtud/curiosa, matrona, enfermera-puericultora.

Recebido para publicação em: 16.01 .15

Aceite para publicação em: 14.07 .15 


\section{Introdução}

O estudo realizado para este artigo, não tem a pretensão de uma investigação histórica, na verdadeira aceção deste conceito. Não dispomos das forças e dos recursos para realizar um estudo dessa natureza, tal como o concebemos. Pretende, no entanto, ser um contributo sério para futuras investigações, deixando antever várias portas de saída para caminhos pouco explorados, entre nós.

Desenvolve-se em três secções, que encerram três períodos históricos: da mulher de virtude à parteira; da parteira à enfermeira-puericultora e desta à enfermeira especialista em saúde materna e obstétrica, com curso de especialização pós licenciatura. Este artigo, da mulher de virtude à enfermeira-puericultora engloba as duas primeiras secções, No entanto, como se pode constatar no desenvolvimento destas secções, a nível de Portugal, coabitaram realidades diferentes, por várias razões. Essa foi a nossa dúvida inicial, que despertou o interesse pelo estudo, a nossa problemática. No âmbito da CEE/CE/EU, no presente, há Estados Membros em que a formação de parteira não se enquadra na formação de enfermagem especializada. Trata-se de um curso de base, como veremos em próximo artigo.

Para a primeira secção, as nossas experiências de vida e profissionais, foram muito importantes, bem como testemunhos obtidos de forma informal, mas intencional, baseados em relatos de mães e avós e do que se dizia sobre o assunto; nas circunstâncias do nosso próprio nascimento, relatadas pela minha mãe e avó e em sete entrevistas formais: três a mulheres que viveram a experiência de serem assistidas por «parteiras», «curiosas» no seu dizer, três mulheres e um homem que relataram o que lhes foi transmitido pelas mães e avós e/ou tiveram conhecimento por outras vias. Também recorremos a documentos de arquivos e consultas bibliográficas.

A segunda tem por base a legislação consultada, de que construímos quadros-síntese sobre a informação nela contida, outras fontes documentais e bibliográficas.

O que testemunhámos e vivemos, ao longo de sessenta anos de enfermeira, foi de grande utilidade para nos guiar nas pesquisas. Consideramos ser nosso dever partilhar o que vivemos e os resultados obtidos nos estudos, mesmo quando estes são modestos. Por exemplo, o que testemunhamos no exercício profissional nos Hospitais da Universidade de Coimbra (HUC), levou-nos a procurar dados sobre tétano neonatal (umbilical) e de tétano devido a manobras abortivas (pé de salsa e outras), nos arquivos do Serviço de Medicina Intensiva daqueles Hospitais, e na Unidade de Cuidados Intensivos do Hospital Pediátrico, ambos pertencendo, agora, ao Centro Hospitalar da Universidade de Coimbra (CHUC) e a procurar dados estatísticos sobre o assunto.

Temos a vantagem de não ser a nossa área de especialização, portanto, observamos os factos, com olhos um pouco mais distanciados, menos apaixonados. Devemos esclarecer que o estudo se foca a nível nacional, dando particular atenção à região centro, embora com uma ou outra incursão sobre o que se passa noutros países, através das Diretivas da CEE/CE/ EU e dos nossos contactos profissionais.

Utilizamos a primeira pessoa do singular, quando se trata de informação de índole pessoal.

\section{Metodologia}

Para a primeira secção - da mulher de virtude à parteira, além da informação obtida por contactos informais e da nossa própria experiência, realizámos sete entrevistas semiestruradas, quatro presenciais $(\mathrm{E} 1,3,4,5)$ e três por via telefónica $(\mathrm{E} 2,6,7)$. Com contacto prévio, quatro senhoras $(\mathrm{E} 2,3,4,5)$, sem contacto prévio um homem (E1) e duas senhoras (E6,7). As idades (anos): 60, 72, 80, 82, 85, 95 e 101 anos. Os contactos iniciais com as quatro senhoras foram feitos através de pessoas de família e, num dos casos através de uma amiga, em casa de quem reside. As entrevistas foram realizadas nas suas atuais residências, à exceção da pessoa mais nova e única do sexo masculino (E1). Esta primeira entrevista surgiu de uma conversa informal, no seu espaço de trabalho, quando numa das nossas visitas nos perguntou: «Então o que anda agora a fazer?» Perante a resposta, logo relatou o que a mãe e a avó lhe contaram sobre o seu próprio nascimento, tendo como «parteira» uma «Mãe-velha». Desconhecíamos o termo, que nos lembrava o Nordeste Brasileiro, despertando a nossa curiosidade. Aceitou o pedido de colaboração e de imediato realizámos a entrevista. Uma entrevistada, mudou da sua aldeia para uma cidade que dispunha de maternidade. Foi seguida durante a gravidez e os filhos nasceram nessa maternidade, a Casa da Mãe, 
criada por Bissaya Barreto (E3). A informação prestada advém do que se passava na sua aldeia natal e do que the era transmitido no seio da sua família. Tanto ela como os irmãos foram aparados por parteiras curiosas. Aliás as outras senhoras entrevistadas foram além da sua experiência pessoal.

Perante os resultados, diferentes do que se fazia crer no meio hospitalar, fizemos uma série de contactos

Tabela 1

Pessoas entrevistadas e particularidades da entrevista telefónicos (CT), alargando a pesquisa, no sentido de confirmar ou infirmar os resultados. O que nos relataram diz respeito ao que se passava em aldeias das seguintes regiões: Entre Douro e Minho, Beira Interior, Norte, Beira-Litoral, Trás-os-Montes e Alto Douro, abrangendo os distritos de Porto, Braga, Leiria, Coimbra, Castelo Branco, Aveiro, Guarda.

\begin{tabular}{|c|c|c|c|c|c|c|c|}
\hline N. ${ }^{\circ} \mathrm{E}$ & Quem & $\begin{array}{l}\text { Ano Nasc. } \\
\text { p. entrev. }\end{array}$ & $\begin{array}{c}\text { Onde/ } \\
\text { tipo }\end{array}$ & $\begin{array}{l}\text { Contact. } \\
\text { Prévio }\end{array}$ & Filhos/Irmãos & Região* & Fonte da informação \\
\hline E1 & $\begin{array}{l}\text { Filho, } 2 .^{\circ} \\
\text { na fratria }\end{array}$ & $1955-60 \mathrm{~A}$ & $\begin{array}{l}\text { L. Trab. } \\
\text { Presenc. }\end{array}$ & Não & 4 & $\begin{array}{c}\text { Entre Douro e } \\
\text { Minho }\end{array}$ & Mãe, avó, outras \\
\hline E2 & A própria & $1933-82 A$ & $\begin{array}{l}\text { Domicíl. } \\
\text { Telef. }\end{array}$ & Sim & 2 & Beira Interior & $\begin{array}{l}\text { O que viveu e } \\
\text { testemunhou }\end{array}$ \\
\hline E3 & Filha & $1943-72 \mathrm{~A}$ & $\begin{array}{l}\text { Domicíl. } \\
\text { Presenc. }\end{array}$ & Sim & 4 & Norte & Mãe e outras \\
\hline E4 & A própria & $1920-95 \mathrm{~A}$ & $\begin{array}{l}\text { Domicíl. } \\
\text { Presenc. }\end{array}$ & Sim & 4 & Beira Interior & $\begin{array}{l}\text { O que viveu, } \\
\text { testemunhou }\end{array}$ \\
\hline E5 & A própria & $1914-101 \mathrm{~A}$ & $\begin{array}{l}\text { Domicíl. } \\
\text { Presenc. }\end{array}$ & Sim & 3 & Norte & $\begin{array}{c}\text { O que viveu, } \\
\text { observou/testem. }\end{array}$ \\
\hline E6 & $\begin{array}{l}\text { Filha, } 1 .^{\mathrm{a}} \\
\text { na fratria }\end{array}$ & $1935-80 \mathrm{~A}$ & $\begin{array}{l}\text { Domic. } \\
\text { Telef. }\end{array}$ & Não & 9 & $\begin{array}{c}\text { Beira Litoral } \\
\text { Leiria }\end{array}$ & $\begin{array}{c}\text { O que observou, } \\
\text { ouviu }\end{array}$ \\
\hline E7 & $\begin{array}{l}\text { Filha, } 1 .^{\mathrm{a}} \\
\text { na fratria }\end{array}$ & $1930-85 \mathrm{~A}$ & $\begin{array}{c}\text { Domicíl } \\
\text { Telef. }\end{array}$ & Não & $\begin{array}{c}13 \\
12 \text { part }\end{array}$ & $\begin{array}{l}\text { Trás-os-Montes } \\
\text { e Alto Douro. }\end{array}$ & $\begin{array}{c}\text { Mãe, tia, outras, } \\
\text { observou }\end{array}$ \\
\hline
\end{tabular}

*Toda a informação se reporta a aldeias.

Nenhuma entrevista foi gravada. A gravação poderia ser intimidativa para as pessoas mais idosas. Optámos por tomar notas breves, redigir logo a seguir um relato, segundo a lógica de encadeamento dos assuntos e, não pela ordem de resposta, validando-o com as pessoas entrevistadas, por telefone ou contacto direto.

Embora de caráter aberto, foi preparado um guião, cujos itens relativos aos aspetos a explorar serviriam para relançar questões a partir das respostas, para as clarificar ou colocar outras sobre itens não abordados. A entrevista assemelhar-se-ia a uma conversa, muito flexível e, que se pretendia agradável para as duas pessoas em presença. A pessoa entrevistada seria ajudada, se necessário, mas não pressionada. Após os cumprimentos e a explicação do assunto em estudo e do contributo que pretendíamos, dos agradecimentos por ter aceite receber-nos e dar a sua colaboração, informar que a confidencialidade e o anonimato seriam respeitados. No que vier a ser publicado não constarão os seus nomes, moradas e outros aspetos identificativos. A informação fornecida será trabalhada e apresentada de forma que a fonte não seja identificável.

Após uma pequena conversa de tipo social seria colocada a primeira questão aberta, ampla, com delicadeza e num registo própria da idade da pessoa entrevistada. As seguintes, seriam encadeadas nesta primeira de forma flexível, voltando atrás se necessário. Houve pessoas que após a entrevista acrescentaram dados, por relembrarem factos ou se terem informado junto de outros membros da família, expressando gratidão por ter desencadeado esta necessidade.

Certificarmo-nos que não havia constrangimento a prestarem a sua colaboração livre, procurando que fosse também esclarecida. Sentimos que o faziam de livre e boa vontade. Não colocaram qualquer reserva sobre a confidencialidade, em relação à informação fornecida.

Recorremos aos arquivos do Serviço de Medicina Intensiva, do CHUC, à Unidade de Cuidados 
Intensivos do Hospital Pediátrico, agora integrado no CHUC, com a autorização e colaboração dos seus directores e enf. chefes, respetivamente Prof. Doutor Jorge Pimentel, Dr Farela Neves, Enf. Eulália Ribeiro, Enf. Helena Mendes (Aposent.), Enf. Conceição Capaz, a quem muito agradecemos.

Para a segunda secção, a consulta da legislação Portuguesa foi fulcral, bem como a bibliográfica selecionada. Partiu da criação do curso de parteiras nas Comarcas, pela Junta de Saúde Pública (1821), dos cursos de parteiras da Faculdade de Medicina da Universidade de Coimbra (FMUC) e das Escolas Médico-Cirúrgicas Lisboa, Porto, depois Faculdades de Medicina (1911). Recorremos ao acervo da Biblioteca Municipal de Coimbra, ao Centro de Documentação Bissaya Barreto (CDBB), Internet e até do contacto com Maria Renilda Nery Barreto (Br.), investigadora na área da história e autora de uma obra muito interessante. Teve a gentileza de nos enviar documento da obra de Mazarém. Não foi possível a consulta ao acervo documental da Faculdade de Medicina de Coimbra devido ao processo de mudança de instalações e de tratamento dos documentos. Construíram-se quadros-síntese, de grande ajuda, por razão de espaço não serão apresentados.

\section{Da mulher de virtude à parteira}

As origens da arte de partejar perdem-se na poeira dos tempos, certamente quando uma mulher mais experiente ajudava outra a parir e, lhe prestava os primeiros cuidados e ao ser que chegava ao mundo. Depois, com a sedentarização, este papel foi sendo confiado a mulheres de sabedoria, mulheres de virtude de que nos fala Collière (1989), iniciando-se, deste modo, a especialização da prática de partejar.

Estas mulheres, também elas mães e avós, que ajudavam outras mulheres a «dar à luz», detendo um saber prático que the foi transmitido por outras ou de cariz intuitivo, que Barreto (2008) denomina de empírico-sensorial, chegaram aos nossos dias e coabitaram com parteiras com formação formal. Daí também as denominarem de «parteiras», acrescentando «curiosas», como fizeram as pessoas entrevistadas, com excepção do primeiro entrevistado que se referiu a «Mãe Velha». Por essas aldeias isoladas, sem meios de comunicação, nem acesso a cuidados profissionais, com parcos recursos económicos, o parto ocorria em casa, com a ajuda da família ou recorriam a estas «parteiras», cujo saber ia passando pela joeira da opinião pública. Os sucessos ou insucessos passavam rapidamente nas aldeias. $\mathrm{Na}$ segunda metade do século passado, ainda existiam nas aldeias vários pontos de encontro: os pequenos comércios que vendiam de tudo, desde artigos de mercearia a granel a artigos de ferragem, por isso se chamavam «vendas», «lojas» ou «mercearias»; as fontes, os lavadouros, o adro da igreja à saída dos atos religiosos; os espaços de artífices, que, em muitos casos, também tinham os seus aprendizes, eram mestres (sapateiro, alfaiate, costureira...), a forja, a olaria..., eram lugares de cavaqueira. Aí se passavam as novidades, se enalteciam as virtudes ou se deitava abaixo a boa fama. Estas mulheres "parteiras", não estavam imunes a este juízo popular, sendo os seus serviços mais ou menos solicitados, de acordo com este julgamento.

No caso das nossas entrevistadas, as "parteiras» gozavam todas de boa fama, com âmbito de atuação que ia além da aldeia onde residiam, sendo caracterizadas positivamente. Eis, alguns excertos ilustrativos: "fazia os partos das mulheres da sua terra e de seis ou sete aldeias..." (E1), "e das aldeias das redondezas" (E2, 6); "às mulheres da família e fora dela" (E7), "foi sempre a mesma parteira, nos meus três partos" (fidelização) (E5).

Já idosas, avós e bisavós, e doentes ainda faziam partos (E1, 2, 6, CT 1). "A Senhora ..., muito entrevada ... vinham das outras aldeias buscá-la e trazê-la a casa, em transportes muares..." (E6), acrescentando que fazia muitos partos, as mulheres tinham muito filhos. São relatadas como pessoas pouco instruídas, algumas não sabiam ler nem escrever, mas "muito respeitadas ..., mulheres de sabedoria" (E1, 6), "as mães falavam dela com muita ternura...", com saber ser e estar: "muito distinta, muito cuidada na sua apresentação e maneiras" (E1); "tinha muito jeito, era boa [na arte de partejar], mulheres boas, amigas do bem" (E5), falando da sua parteira e doutras; "habilidosas. Pessoas do bem" (E4); "muito arrumada nela própria, tinha aprumo pessoal" (E7). "muito responsável e sabedora" (E2); "uma postura discreta, quando nos encontros as mulheres se envolviam em falatórios, ficavam fora disso" ( $\mathrm{CT}_{2}, \mathrm{E}$ ). Em relação à higiene: "muito asseada" (E1); "era de gente muito esmerada, limpa, asseada" (E5); "de higiene muito apurada ... tinha o culto da água fervida”(E7).

São vistas envoltas numa auréola de missão, sempre disponíveis, deixando os seus afazeres caseiros 
ou o conforto da sua cama, quaisquer que fossem as condições meteorológicas, para acudir a uma mulher em trabalho de parto, como Valente (2013, p. 39) tão bem descreve um nascimento ocorrido em 19/01/1954. Esta característica é referida em todas as entrevistas e contactos não formais. Pelo que ouvi contar às avós e mães da minha e doutras aldeias, ficaria bem, representá-las, envoltas num xaile, preto e de lã, no relato de Valente (2013; E6, CT 4 ), segurando uma lanterna, a azeite ou petróleo, que iluminava carreiros e caminhos em noites escuras, as claras tinham o brilho das estrelas e o luar a projetar sombras fantasmagóricas. Geralmente, faziam o trajeto acompanhadas pelo homem da família da parturiente, que foi solicitar os seus serviços, ou simplesmente comunicar-lhe que "tinha chegado a hora», nos casos em que havia contacto prévio e até algum seguimento da grávida, instruindo-a sobre o ritmo e intensidade das contrações, o que era preciso ter preparado.

Em todos os relatos, entrevistas e contactos não formais (CT) foi referido que não levavam dinheiro pelos seus serviços, "fazia este trabalho com espírito de missão" (E1), "mas as pessoas tinham um olhamento, davam o que queriam, em géneros"(E2, 3), "sempre se tinha um olhamento, mas havia pessoas que nem para elas tinham de comer, por isso não podiam retribuir"(E4); "dávamos-lhe coisas de casa, géneros de alimentação, que ela vivia pobre. $\mathrm{Na}$ nossa casa trabalhava-se muito na lavoura, mas havia fartura" (E5);

As mães tinham muita ternura por ela, sempre que havia uma novidade (frutas, legumes, matança do porco...), não se esqueciam de lhe levar um miminho... Quando ficou mais limitada, tinha sempre quem a levasse à missa ou onde precisava, nas carroças. Na minha aldeia, duas famílias tinham «charretas» também a levavam. (E6)

Foi focada a relação com o médico: "era respeitada pelo médico" (E1); "Os médicos tinham muita estima por ela" (E6, CT $)$.

Quando o parto era difícil "mandavam chamar o médico, de avença" (E3); "mandava chamar o Dr..., ia um homem a cavalo chamá-lo..." (E7)", chamava o Dr...que era de outra especialidade $\left(\mathrm{CT}_{1}\right)$. Percebemos, em vários contactos informais uma certa cumplicidade entre médico e «parteira».

Interessante e, muito carregado de simbolismo, é o termo «ajudar a dar à luz», mas também se dizia «aparar». Ouvi várias vezes dizer: a «Senhora (dizendo o nome) que aparou os meus filhos». A minha mãe disse-me várias vezes, a propósito do meu nascimento (25/04/1934), a "Senhora ... que te aparou, percebeu que o parto da tua irmã gémea estava fora do seu âmbito e mandou chamar o médico..."(CT). Realmente, em muitos casos era mesmo só aparar, a natureza encarregava-se do parto. No meu caso, nem isso, pois nasci «ão rápido que caí no penico», por ser muito «miudinha», segundo testemunho da minha mãe, da minha avó e outros. Nunca indaguei se o parto foi de pé. A minha mãe, apesar do parto muito difícil da minha gémea e de a ter perdido, sempre se referia à «parteira» com respeito e gratidão. Pelo que me foi dito, a «parteira» não a abandonou e colaborou com o médico, preparou os «ferros» (fórceps). No sótão da casa dos meus avós, onde o parto ocorreu, existia uma panela de esmalte branco grande, que ao indagar o porquê de ali estar a minha avó disse: «por ter servido para ferver os ferros, que tiraram a tua irmã gémea, nunca mais teve a serventia a que era destinada». Sou a primeira na fratria. O segundo parto ocorreu na Clínica Obstétrica Daniel de Matos (abrev. CO), vulgarmente Maternidade Daniel de Matos (MDM). O terceiro (1940) e o quarto (1942) ocorreram em casa, assistidos pela mesma parteira (de boa fama), o quinto e o sexto na MDM, desconheço a razão, visto que os anteriores tinham corrido bem.

Não foram referidos os termos «comadre» $\mathrm{e}$ «aparadeira (Barreto, 2008), no entanto tenho ideia de ouvir o termo comadre nas nossas aldeias. $\mathrm{O}$ termo comadre também é interessante e significativo (cum + mater $=$ com a mãe). No Reino Unido e Irlanda persiste a denominação «midwife»/com a mulher, na França e Luxemburgo o de «sage-femme»/mulher sábia ou de sabedoria (CE, 2005, Dir.36).

Todos os partos, relatados neste estudo, ocorreram no domicílio, situando-se no período de 1930 (E7) a 1961 (E2). Neste período, existiam em Portugal parteiras formadas pelas faculdades de medicina e pelos institutos maternais. Nos contactos pós entrevistas foi sinalizada uma «parteira»/curiosa numa vila do distrito da Guarda, cujo perfil corresponde ao relatado pelas entrevistadas, que ainda fazia partos em 1974.

Os partos ocorreram de dia e de noite. As parteiras foram chamadas pelos maridos, mães, vizinhas...

O parto, tinha o seu ritual: o lavar as mãos (E1, 2, 4, 5), arregaçar as mangas e lavar a preceito as mãos, antebraços até acima dos cotovelos $\left(\mathrm{CT}_{3}\right)$; Terem preparado lençóis, duas toalhas brancas de linho (E1, 
7, $\mathrm{CT}_{3,4}$ ) ou de turco $(\mathrm{E} 2,6)$ uma para aparar a criança e outra para a enxugar depois do banho (E1, 2), no entanto nem todas as mães dispunham destas toalhas, algumas utilizavam duas fraldas feitas de panos usados, por serem mais macias (E5), "toalhas limpas das que havia, mesmo trapos, por extrema pobreza de algumas famílias" (E4), as faixas, a roupa para a criança, também de pano usado, "a desinfeção da tesoura para cortar o cordão umbilical" (E2), "ferver a tesoura" (E7), "traziam o material para cortar e tratar do cordão umbilical" (E1, E2, E7). "O banho na bacia especial (E1), de esmalte, quando a havia" (E6). Foi descrito com pormenor os cuidados das mães na preparação de faixas e demais precisos para o parto, que guardavam de uns para outros filhos $\left(\mathrm{E} 6,7, \mathrm{CT}_{3}\right)$. $\mathrm{O}$ parto: as três senhoras que viveram a experiência de ser assistidas por «parteiras» curiosas (E2, 4, 5) relataram que o parto ocorreu deitadas na cama e a parteira «ajudou a fazer força» (ajuda externa no período expulsivo?). À pergunta: «A parteira meteulhe as mãos dentro para ajudar a criança a sair?» As respostas foram negativas, inclusive a E2, em que o primeiro parto foi mais difícil por o bebé ser volumoso, "até rasgou um bocadinho" (E2).

Depois do parto cuidavam primeiro da mãe e a seguir da criança: "cuidou de mim, meteu-me na cama e depois do banho, colocou o menino junto de mim" (E2), "cuidavam de mim e depois do banho colocavam as crianças junto de mim" (E4). Esta senhora teve quatro filhos, em diferentes locais e quatro parteiras diferentes, por acompanhar o marido onde ele tinha trabalho. Interessante é a expressão da E5 "e aconchegava as crianças a nós” (E5). Pormenorizado e interessante é a seguinte descrição do parto (E7):

Preparava-se uma grande panela para ferver a água, pois usava muita água e muito bem fervida. Tudo era fervido, a tesoura, o fio de linho para atar a envide [porção do cordão que fica ligado ao recém nascido], o penso de protecção, a água do banho ao bebé também era fervida.

Normalmente, os bebés não nasciam na cama. A mulher ajoelhava-se/agachava-se no chão, em cima de um cobertor, coberto com um lençol de linho. Depois do nascimento, atava o cordão, deitava a parturiente na cama, cuidava dela e só depois cuidava da criança, dava-lhe o banho, cortava o cordão, protegia-o com um bocadinho de pano de linho fervido e colocava a faixa também feita de pano de linho muito usado, vesti-a, usavam-se os cueirinhos, embrulhava-a e colocava-a junto à mãe, aconchegando-a a ela. E já estava preparado um caldo de galinha para a mãe. Nos dias seguintes até cair a envide vinha dar banho ao bebé e fazer o penso. Usava uma bonequinha feita do linho mais puído, fervida e molhada em água morna fervida para limpar o coto. O resguardo era de pelo menos uma semana (a caldos de galinha).

O que esta senhora observou em relação ao nascimento dos irmãos mais novos, é que a mãe começava $\log$ a trabalhar. Recordou que a mãe se tinha comprometido a fazer um jantar para um grupo de caçadores, a criança nasceu, mas ela fê-lo à mesma, encobrindo a barriga com um xaile para que os caçadores não percebessem que o parto se tinha dado. No primeiro filho, as parteiras vinham dar o banho à criança, como no relato acima, nos filhos seguintes a mãe, já mais segura, dava-o ela. Em relação ao puerpério, o termo usado foi resguardo, num período de 30 dias para as meninas e 40 para os meninos (E2), admitindo que no segundo parto, uma menina, começou a fazer a sua vida passados poucos dias. E as outras duas senhoras os relatos foram idênticos. Em relação a este aspeto, quando contactei de novo a Senhora da E2, a fim de validar o que tinha escrito, disse-me que se tinha esquecido de me dizer que uma mulher se partejava a si própria. «Mas, contou-me, era a sua parteira». "Essa também. É uma cá da aldeia. Preparava tudo quando chegava a hora, depois do parto, tratava das crianças, embrulhava-as, metias na cama, a seguir ia lavar a roupa do parto e, só depois se deitava junto às crianças. Foi assim nos seus cinco filhos". «Mulher valente», respondi. «E, olhe que era muito franzina, dez reis de gente».

À questão: era usado o termo resguardo ou regimento? Todas as respostas confirmaram que o termo usado era resguardo. Esta questão surgiu porque em jovem ouvi o termo «regimento» numa aldeia serrana perto de Fátima, com os tais 30 e 40 dias. Reencontrei-o no art. ${ }^{\circ} .^{\circ}$ do regulamento do exame de aspirantes a parteiras ( $D G, n^{\circ}{ }^{\circ} 156,1870$ de 16 de Julho). O exame é público e versa sobre as seguintes matérias: I...; II...; III. Dequitadura e regimento; IV ...;

O pegar-lhe pelos pés e as palmadas nas nádegas («nalgas» no dizer de algumas idosas, da minha e doutras aldeias) para a fazer chorar e, assim, abrir os pulmões não foi referido nas entrevistas.

O ritual do batismo, se a criança parecia não sobreviver, 
também não foi referido. Uma das entrevistadas (E5), teve um parto prematuro, «o cordão do sangue partiuse» (placenta prévia?). Era uma menina, de sete meses de gestação, não foi batizada por ter nascido sem vida. Não teve cerimónia fúnebre, mas foi enterrada no cemitério, dentro duma caixa de sapatos, por ser muito pequenina. Este dado vem contra o que se aprendia na catequese, «em caso de dúvida batiza-se sob condição».

Relacionado com o batismo, algumas parteiras levavam a criança a batizar «levar a criança à pia», diziase. "A parteira era convidada em sinal de respeito e agradecimento" (E4,5).

As orações, para que a parturiente tivesse uma «hora pequenina» e a criança viesse bem, embora admitissem que as faziam, por serem muito religiosas, só foram referidas explicitamente em dois casos

Era muito religiosa, benzia-se e fazia uma série de orações/preces. Conseguia incorporar o lado místico no seu saber. Tinha o dom de saber acalmar as parturientes. Por exemplo primíparas e as que por medo ou qualquer outra razão se descontrolavam. (E1)

"Benziam-se, oravam ao Pai do Céu para que tivesse uma hora pequenina". (E4)

Contam-se histórias, lendas sobre essa auréola mística, relacionadas com outros poderes, que não os de partejar, como a de Pitágoras (570 a.C.- 490-500 a.C.), em que se diz que o nome significa altar da Pítia ou que foi anunciado pela Pítia, pois a mãe ao consultar a Pitonisa soube que a criança seria um ser excecional (Biografia, Internet). E a de Pelé, o Rei, de seu nome Edson Arantes do Nascimento. A «parteira», ao dar-lhe as palmadas para o fazer chorar, dissera: «este vai ser rei», não encontrámos este dado na consulta às biografias de Pelé, na Internet.

Foi focado o secretismo em relação ao parto perante os outros filhos, dando-lhes depois uma justificação para o aparecimento da criança (E6 e CT).

Infelizmente, os rituais higiénicos acima referidos, ainda que rudimentares, nem sempre seriam cumpridos, porque o parto se dava sem qualquer assistência ou porque quem assistia não seria rigoroso no seu cumprimento e, sobretudo, pelas deficientes medidas sanitárias de vacinação, o tétano neonatal existia e persistiu ainda na segunda metade do Século XX. Testemunhámos esta dura realidade no nosso exercício hospitalar nos Hospitais da Universidade de Coimbra (HUC), sobretudo nas rondas com funções de chefia, por escala, das $20 \mathrm{~h}$ às $8 \mathrm{H}$ do dia seguinte, de 1958 ao final de 1967. A enfermeira chefe de ronda tinha a seu cargo todos os serviços femininos, o Serviço de Pediatria, os Socorros Urgentes e o Serviço de Medicina Intensiva (SMI), a partir da sua abertura em 1960, denominado então Serviço de Reanimação. Na consulta aos arquivos do SMI-CHUC, encontrámos um estudo sobre «Terapêutica do Tétano» de Carrington, Gomes e Oliveira (1969), que apresenta dados estatísticos fornecidos pela Direcção Geral de Saúde (DGS), relativos a 1960, 1965, 1966 e 1967, num total de 1377 casos, com 887 óbitos (65,14\%). Em relação ao então Serviço de Reanimação são referenciados 78 casos, sendo 9 neonatais e 3 postabortum, com 23 óbitos (29, 47\%). A razão de não constarem os anos de 1961/62/63/64, relativo aos dados da DGS, a nível nacional, não é referida, nem até que ano se referem os do Serviço do Serviço de Reanimação (1967/68/69?). Este Serviço começou a funcionar em condições muito precárias, só com duas camas e um ventilador, num espaço exíguo, daí que não poderia haver uma total cobertura a todos os casos graves de tétano.

$\mathrm{Na}$ segunda década de funcionamento daquele Serviço (1970-1979, incluídos), nos livros de registos constam 29 casos de tétano neonatal, as crianças, na data de admissão tinham entre 4 a 13 dias. Este dado é importante, visto ser provável corresponder ao período de incubação do tétano e sabe-se que quanto mais curto for esse período mais grave é o prognóstico. O ano com mais casos é o de 1975, com sete casos, seguido do ano de $1971 \mathrm{com}$ seis. Com a abertura do Hospital Pediátrico (HP) em 1 de junho de 1977, encontramos três crianças transferidas para este hospital (livres de perigo) e em 1979 um caso grave transferido do HP para o SMI-HUC. A Unidade de Cuidados Intensivos do HP abriu em 1980. Nesta década, em relação a tétano obstétrico e de manobras abortivas não é referenciado nenhum caso, embora se encontrem registados casos de mulheres em período fértil. O diretor do serviço está convicto que os houve, como eu própria. Pode pôr-se a hipótese de estarem contidos nos das mulheres em período fértil, mas não especificados, como medida protetora da mulher, dadas as leis vigentes nessa época.

Solicitámos colaboração ao HP e especificamente à chefia da Unidade de Cuidados Intensivos. O nosso pedido foi muito bem acolhido tanto pela Senhora Enf. Supervisora Eugénia Morais, como pela Sr. 
Enf. Chefe Conceição Capaz que realizou o trabalho de consulta aos livros de registo, por nós, com a autorização do diretor da Unidade. Em novembro de 1979 há o registo de uma criança de 15 dias, e até ao final de 1985 um total de nove casos, com idades entre 6 a 28 dias, sendo quatro com 10 dias. Na década de noventa, dois casos, uma criança em 1991 com 13 dias e outra em 1995, referenciada como recém-nascida. Portanto, um total de 11 crianças com tétano.

O tétano só passou a ter notificação obrigatória a partir de 1958, o que explica não encontrarmos dados estatísticos antes desta data. Correia (1937, fornece-nos dados estatísticos de outras doenças infeto-contagiosas dos anos 30, mas não de tétano. Também não consta na grande lista de doenças infeto-contagiosas, de declaração obrigatória, inserta na Portaria 13:031, do Ministério do Interior, que substitui a Portaria n. ${ }^{\circ}$ 10:169/1942 (DG, n. ${ }^{\circ} 4$, de 5/01/1950). As atividades inerentes à obrigatoriedade de vacinação anti-tetânica só são fixadas pelo Decretolei $\mathrm{N}^{\mathrm{a}} 44198$ de 20/02/1962 e Portarias 19058 de 3/03/62 e 19045 de 18/01/1963 (Carington, Gomes \& Oliveira, 1969).

À pergunta se constavam notícias de insucessos destas parteiras, de mulheres e crianças que morreram no parto, as respostas foram negativas. Como acima descrito houve uma nado-morta prematura, decorrente de situação de risco, mas não foi atribuída a inépcia da «parteira».

A E6 dá a seguinte explicação "as mulheres trabalhavam muito no campo e até ao fim da gravidez, talvez isso facilitasse o parto". O relato da E2, vai nesse sentido: "no dia em nasceu a minha filha ainda trouxe da eira para casa 22 alqueires de milho". A E7 tinha uma gémea que veio a falecer, mas não no parto. Nunca aprofundou o assunto. A Senhora da E4 faleceu-lhe um menino de 14 meses e uma menina com 10 meses, contagiados pelo sogro que era tuberculoso. Tive experiências destas nas rondas. Recordo um caso bem desagradável de uma criança de meses contagiada pelos avós e, era a segunda que a mãe perdia pela mesma causa. Os dados estatísticos da DGS, reportados por Correia (1937) em relação à tuberculose são assustadores. A média anual de óbitos foi: 1902-1910 de 6533; 1916-1925 de 9024; 1930-1933 de 12310, com taxas em relação a 10000 habitantes de 11, 4; 14,9 e 18 respetivamente. 0 autor adverte para as mortes de causa ignorada, que a distribuição por distrito faz supor incluir os de tuberculose (p.264 a 267). A situação era ainda mais negra para Bessa (1986), afirmando que nos anos 30 havia pelo menos cerca de 150000 tuberculosos, dos quais cerca de 40000 eram contagiantes. A primo-infeção da criança e adolescente era frequente, assim como a meningite tuberculosa e morriam por ano cerca de 30000 portugueses (p.15). A Obra de Protecção à Grávida e Defesa da Criança (OPGDC), de Bissaya Barreto, enraíza-se no estado deplorável da Assistência Materno-Infantil e abandono da criança, bem como na sua luta contra a tuberculose de que o Prof. Doutor Luís Raposo, primeiro Diretor desta obra (1931), o Dr. José Santos Bessa, Diretor Clínico (1986) e o próprio Prof. Bissaya Barreto nos dá conta em vários escritos. Ao fechar a entrevista com a seguinte afirmação «pelo que me disse posso concluir que estas «parteiras» curiosas eram bem vistas e muito estimadas?». A resposta foi afirmativa, tanto nas entrevistas formais, como noutros contactos. A senhora da E2, respondeu que havia uma de... (disse o nome da aldeia) que tinha fama de fazer abortamentos. Falava-se isso na sua venda, e nos nomes das mulheres que recorriam a essas práticas. «Estavam dois ou três dias metidas em casa e depois apareciam desembaraçadas». Também a Senhora da E3, referiu que quando menina ouviu dizer aos trabalhadores da casa agrícola de seus pais: "fulana mandou mais um rio abaixo". Perguntou à criada o que queriam dizer, que lhe explicou que se tratava de aborto. Mais tarde houve um caso muito triste, em que uma mulher o fez sem o marido saber, este entrou em depressão... Não se sabia a quem recorriam e o que faziam.

De realçar que não eram só em aldeias isoladas, serranas que estas «parteiras» operavam. Umas sim, outras bem perto das capitais de distrito, por ex. oito $\mathrm{km}$ de Leiria, no meu caso $17 \mathrm{~km}$ de Coimbra, metade da distância das sedes de concelho.

\section{Da parteira à enfermeira-puericultora}

Dotar a parteira com alguma formação formal remonta ao início da década de 1820, com o Regulamento Geral de Saúde Pública (18/10/1821), apresentado às cortes por um grupo de deputados. Este integrava no novo ordenamento a Junta de Saúde Pública, como órgão central administrativo (Art. $1^{\circ}{ }^{\circ}$ ). Engloba a parteira no grupo dos empregados da saúde, embora no fim da linha: médicos, cirurgiões, boticários e parteiras. Propõe a criação de duas escolas regulares de Cirurgia uma em Lisboa e a outra no Porto e a 
reforma da Faculdade de Medicina da Universidade de Coimbra, a fim de que nela se «pudesse fazer um estudo de Cirurgia completo». Em relação às parteiras propõe a criação de um curso, nas comarcas, onde houvesse um cirurgião instruído na arte de Obstetrícia, a Junta de Saúde Pública conceder-lhe-ia licença para abrir um curso anual de partos para as mulheres que se propusessem ser parteiras, tendo como exigência saber ler e escrever (Carneiro, 2007). Não cabe neste artigo entrar em grandes detalhes no percurso efetuado, Marinha Carneiro a partir da sua tese de doutoramento (2003), deixa um manancial de informação, que situa nos contextos sociais e políticos, percebendo-se o empoderamento dos cirurgiões obstetras nos seus artigos (2005 e 2007). Igualmente os artigos de Maria Renilda Nery Barreto, nos seus artigos (2007, 2008), a partir da sua dissertação de Mestrado (2000) e tese de doutoramento (2005). Os artigos destas autoras são de consulta obrigatória, tanto pela extensa bibliografia consultada como pelas suas próprias produções.

Com a reforma acima referida, em 1836, é aprovado o Plano Geral de Estudos da Faculdade de Medicina da Universidade de Coimbra (FMUC) e criado o «Curso de Arte Obstetricio» destinado a parteiras, dirigido pelo Lente da 7. ${ }^{\text {a }}$ Cadeira "Partos, Moléstias das Mulheres de Parto e dos Recém-Nascidos" (Carneiro, 2007, p. 330), e Decreto de 5 de Dezembro de 1836 (DG, n. $\left.{ }^{0} 295,5 / 12 / 1836\right)$. A Secretaria de Estado dos Negócios do Reino (SENR) pelo Decreto de 29 de Dezembro de 1836, transforma as Reais Escolas de Cirurgia de Lisboa e Porto, criadas em 1825 (Alvará das Escolas Cirúrgicas, assinado por D. João VI, em 25 de Junho), que passarão a denominar-se Escolas MédicoCirúrgicas de Lisboa e Porto ( $\left.D G, \mathrm{n}^{-}{ }^{\mathrm{0}} 3,4 / 01 / 1937\right)$. Entre outros aspetos, neste Decreto são criados o Curso de Medicina de 5 anos, com 9 cadeiras e o Curso de Parteiras, de 2 anos, com a $6^{\mathrm{a}}$ cadeira, com

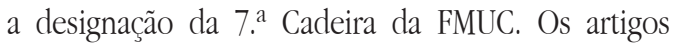
$140^{\circ}$ a $144^{\circ}$ referem-se especificamente ao Curso de Parteiras, assim:

Art. $140^{\circ}$ - O curso é bienal, teórico e prático destinado especificamente à instrução de parteiras;

Art. $141^{\circ}$ - O curso teórico será lido pelo Lente de Partos e compreenderá as lições designadas por ele;

§ único - O curso prático terá lugar na enfermaria respectiva, debaixo da inspecção e direcção do mesmo lente;
Art. $142^{\circ}$ - As aspirantes terão matrícula separada na aula de partos e um lugar decente na mesma, onde possam ouvir as prelecções que forem designadas pelo Lente, na forma de articulado antecedente;

Art. 143. - Findo o curso bienal serão as aspirantes examinadas perante um júri especial destes exames, composto pelo Lente do ano, lente das operações e um dos cirurgiões que tiverem serviço no hospital, nomeado pelo Conselho da Escola:

$\S 1^{\circ}$ - O exame versará sobre teoria, prática, acidentes...

$\S 2 .^{\circ}$ - A aprovaçãa depende da pluralidade absoluta dos votos e verificando-se será conferida às aspirantes, gratuitamente, Carta de Parteira, passada pelo Secretário, assinada pelo Diretor e selada com o selo da Escola. Na carta será sempre inserta a cláusula proibitiva do uso de instrumentos cirúrgicos sem a assistência do Professor;

Art. $144 .^{\circ}$ - No acto da matrícula juntarão as aspirantes certidão de saberem ler e escrever passada por algum professor público, precedendo o exame.

De notar o termo aspirante (a parteira), enquanto para o curso de medicina é usado o termo aluno. Também as aulas são lidas pelo Lente e não exige mais que saber ler e escrever, enquanto para os alunos remete para um ensino mais ativo.

Em 1840, em 3 de Abril, SENR dota as Escolas MédicoCirurgicas ( $D G$ n. $.^{\circ} 289,23 / 04 / 1840$ ) com regulamento mais minucioso que o do Decreto de 1836. No que se refere ao Título II - Curso de Parteiras, art. 191. ${ }^{\circ}$ o 205. ${ }^{\circ}$, além de algumas particularidades, de notar:

Art. $193{ }^{\circ}$ - a exigência de juntar ao requerimento ao Director para a matrícula certidão de idade de 20 anos e atestado de vida e costumes, mantendose o saber ler e escrever.

Art. $197^{\circ}$ - O exercício prático na enfermaria deve ser feito por turmas de aspirantes. Cada uma destas turmas se conservará na enfermaria 24 horas, não se podendo retirar antes de ser rendida por aquela, que por escala lhe seguir. Art. $198 .^{\circ}$ - As aspirantes de serviço, estarão subordinadas à Parteira Superior que estiver de semana, a qual as fará assistir aos partos, vigiar as parturientes, prestar-lhes socorros ... incumbir-lhes também qualquer serviço 
relativo às mulheres grávidas, parturientes ou puérperas...

Art. $199 .^{\circ}$ - As aspirantes ... farão diários do que ocorreu de mais singular às mulheres que forem entregues ao seu cuidado e vigilância, escreverão no respectivo livro a filiação das pejadas que de novo entrarem na enfermaria e farão o assentamento da apresentação, posição dos fetos que nascerem, do sexo, peso e comprimento, assim como anotarão o tempo que o parto durou. Art. $200 .^{\circ}$ - As faltas das aspirantes serão contadas do mesmo modo que as dos alunos da Escola Médico-Cirúrgica e dos farmacêuticos.

Art. 201. ${ }^{\circ}, 202 .^{\circ}, 203 .^{\circ}$ - Dizem respeito às exigências de admissão ao exame de fim de curso bienal, ao exame a ser feito por turmas de quatro aspirantes, assuntos versados sobre teoria e prática e tempo para os examinadores e examinandas.

Art. 204. - - Refere-se à Carta de Parteira a passar às aspirantes aprovadas nos exames, mantendo a cláusula de proibição anterior. Surge uma nova particularidade: «A aspirante que for reprovada uma vez poderá ser admitida a novo exame, frequentando mais um ano. A que for reprovada segunda vez não será mais admitida a matrícula, nem a exame».

Art. 205. - - Refere-se à gratuitidade do curso. Todo o Curso de parteiras é gratuito; as aspirantes não pagarão nada por matrícula, por exame, nem pelas cartas (Ministério e Secretário de Estado dos Negócios do Reino, 3 de Abril de 1840 - A Rainha -Publicado no $D G$ n. ${ }^{\circ} 289$ de 23 Abril de 1840).

O foco é nitidamente colocado no exercício prático, em termos atuais ensino clínico, por turmas de aspirantes 24h/24h, sob a supervisão da Parteira Superior, enquanto no anterior não é referida esta figura, mas sim a inspeção e direção do Lente da Cadeira. Compreende-se, pela não existência de parteiras diplomadas. A grande novidade é a exigência explícita de registos, especificando o que deve ser registado. Também afirma de forma inequívoca a gratuitidade de todo o curso, desde a matrícula à carta de parteira.

Certamente a obra «Recopilação da arte dos partos, ou quadro elementar obstetrício para instrução das aspirantes que frequentam o curso de partos» de Joaquim Rocha Mazarém (1838), não foi indiferente a esta tónica inovadora, assim como toda a ação prática do seu autor. Mazarém, depois da sua experiência de docência no Brasil (Escolas de Medicina do Rio de Janeiro e Baía), volta a Portugal em 1821. Além de Cirurgião da Armada e da Casa Real (Real Câmara), foi Chefe da Enfermaria de Santa Bárbara do Hospital de S. José, Diretor e Professor da Real Escola de Cirurgia de Lisboa (4. ${ }^{a}$ cadeira) e Lente da Escola Médico-Cirurgica (sexta cadeira) de Lisboa até ao seu falecimento, em 1849 (Barreto, 2007). A autora, neste artigo, analisa esta obra, no formato de livro de bolso, de fácil manejo e transporte, desde o tipo de linguagem utilizada, ao seu conteúdo, situando-a face ao universo nacional e internacional. Nela, Mazarém mostra claramente, em relação às parteiras, de não se incluir na sua própria afirmação: "o opróbrio de ignorante deveria recair sobre aqueles que lhe têm vedado os meios de adquirirem a necessária instrução e, pelo menos o indispensável para o exercício da sua arte" (Barreto, 2007, p. 7). A autora realça que as orientações e recomendações que deixa, revelam que Mazarém é sensível à angústia da mulher em trabalho de parto, aos seus medos, isto é, às suas reações emocionais e psicológicas, enquanto manuais de grande repercussão, escritos por cirurgiões ingleses, não contêm nenhuma pista sobre o assunto (p.14). Neste aspeto é inovador, como também aponta o papel educativo das parteiras em relação às mães, mesmo sobre os aspetos a ter em atenção na escolha das amas de leite.

A partir desta disposição legal (regulamento de 1840), outras foram importantes, como a Lei de 18 de Setembro de 1844 que reorganiza o Conselho de Saúde Pública, criado pelo Decreto de 3 de Janeiro de 1837, dando-lhe enquadramento de «Autoridade Superior» (Carneiro 2007), o que explica algumas determinações posteriores, como a de 13 de Janeiro de 1851 (não foi encontrada), que regulamenta as suas funções de concessão de licença, estabelecendo duas vias:

1. As aspirantes a parteiras em Lisboa, Porto e Coimbra teriam de se habilitar perante os delegados do Conselho de Saúde Pública, só sendo admitidas a exame, a realizar em hospitais, desde que fizessem prova de frequência regular dos cursos das Escolas Médicas, sendo-lhes então passada uma carta para o exercício da actividade. 2. As aspirantes a parteiras que pretendessem exercer a sua actividade exclusivamente em lugares onde não existisse alguma parteira habilitada pelas Escolas Médicas podiam fazê-lo, 
sem dependência do requisito do curso bienal, mas submetendo-se a exame perante o Conselho de Saúde Pública; estes exames a realizar seriam do mesmo tipo dos acima citados, sendo que as cartas a conceder conteriam uma nova cláusula, a saber, a designação do lugar onde exclusivamente the era permitido o exercício da profissão (Carneiro, 2007, p.336).

O Conselho de Saúde Pública foi extinto por Decreto de 3 de Dezembro de 1869. Daí que em 13 de Julho de 1870, o Ministério dos Negócios da Instrução Pública, 1. ${ }^{a}$ Repartição ( $D G$ n. ${ }^{0} 156$ de 16/07/1870) estabelece o programa para o exame de parteira:

Art. $1^{\circ}$ - ... podem ser feitos na Faculdade de Medicina da UC e Escolas Médico-Cirurgicas de Lisboa, Porto e Funchal e Delegados de Saúde nos distritos que não são sede de Faculdade ou Escola.

Art. 2. - - As aspirantes apresentam os seus requerimentos ao Reitor da Universidade ou ao Director de qualquer das Escolas Médico Cirúrgicas à escolha das examinandas e ao Delegado de Saúde do Distrito onde tiveram residência por mais de um ano consecutivamente, nos termos do art antecedente.

Art. 3 - ... instruem os seus requerimentos com os seguintes documentos:

I Certidão de idade de 21 anos;

II - Atestado de bons costumes, passado pelo pároco das freguesias e pelos administradores dos concelhos ou bairros onde tenham residido nos últimos dois anos;

III - Certidão de Facultativo onde se prove que não padecem de moléstia contagiosa ou de alguma outra que as impossibilite de exercer para o que pretende habilitar-se e que além disso foram vacinadas ou tiveram bexigas;

IV - Certidão de exame com aprovação de instrução primária, feito em qualquer liceu ou escola oficial ou livre de instrução primária ou secundária;

V Certidão de que não foram reprovadas nas matérias dos exames de parteiras dentro dos últimos seis meses em qualquer das escolas designadas no art. $10^{\circ}$ ou perante delegados de saúde.

$\S$ Único - Além destes documentos as requerentes podem juntar outros, que julguem aproveitarlhes.
Os art. $4 .^{\circ}$ ao $10 .^{\circ}$ vão da verificação da legalidade do processo, do exame (público) e das matérias que versa, constituição do júris e como se processa o exame (tempo para examinador e examinanda), aprovação ou não, registo em livro próprio... e, a advertência de que não sendo aprovada não pode ser admitida a nova prova senão decorridos seis meses.

O Art. $11^{\circ}$ - A carta de aprovado é passada pela Universidade, pelas Escolas Médico-Cirurgicas, pelos Delegados de Saúde onde o exame tem lugar, declarando-se na mesma carta a proibição de usar instrumentos, de provocar manualmente o parto e de prescrever tratamento algum no estado de gravidez, parto e puerpério;

Art. $12 .^{\circ}$ - As parteiras aprovadas perante 0 delegado de saúde, estes passam uma licença para exercer a sua arte durante um ano no próprio distrito e só depois expedem a carta se elas, pela prática provarem a sua aptidão;

Art. $13 .^{\circ}$ - Tanto estas cartas como as da Faculdade de Medicina e Escolas, a a abrigo do art. 11. ${ }^{\circ}$, se declara expressamente que não podem exercer nos concelhos onde exista parteira habilitada com frequência provada e exame na Faculdade de Medicina e Escolas Médico-Cirurgicas.

Art. $14{ }^{\circ}$ - As propinas e emolumentos pelo exame e cartas são estabelecidos pelo Decreto de 3 de Janeiro de 1837.

De notar, como novidade, a Escola Médico-Cirúrgica do Funchal. Não encontrámos legislação sobre a criação desta Escola. O art. 2. ${ }^{\circ}$ traz a inovação interessante e avançada para a época, de as aspirantes apresentarem os seus requerimentos ao Reitor da Universidade ou Diretor das Escolas Médico-Citúrgica à escolha das examinandas. No entanto, quando os requerimentos são dirigidos ao Delegado de Saúde do Distrito são condicionados à residência, com caráter consecutivo, por mais de um ano. Mantém a proibição inserta na carta do uso de instrumentos cirúrgicos, para Mazarém o fórceps e a alavanca (in Barreto, 2007, p.14), acrescentando outras (art. 11. ${ }^{\circ}$ ), além das restrições contidas nos art. $12 .^{\circ}$ e $13 .^{\circ}$.

Em 1901, o Decreto da reforma da UC, com base no art. 18 da Lei de 12 de Junho de 1901, em relação à Faculdade de Medicina (FM), Ministério dos Negócios do Reino, estabelece (art. 114º) o Curso Geral da FC, com 15 cadeiras. E o Curso de Obstetrícia, que consta de dois anos de frequência da $12 .{ }^{a}$ Cadeira Obstetrícia, moléstias das puérperas e recém-nascidos 
do Curso da Faculdade, estabelecendo a exigência de que durante estes dois anos as alunas são obrigadas a assistir a todos os partos que ocorrerem na respetiva enfermaria (art. 119. ${ }^{\circ}$ ). No fim dos dois anos as alunas fazem um exame teórico e prático, perante um júri composto por três vogais, sendo presidente o prof. da cadeira de obstetrícia...(art. 120. ${ }^{\circ}$ ). No art. 121. ${ }^{\circ}$ há a advertência de que «a frequência faz-se especialmente para este curso e não pode ser levada em conta para o curso geral». De notar que é usado o termo alunas para este curso e, não o de aspirantes, como é utilizado o de alunos para o curso geral (O Presidente do Conselho de Ministros, Ministro e Secretário de Estado dos Negócios do Reino, assim o tenha entendido e faça executar, 24/12/1901). Publicado no $D G$, N. $^{\circ} 294$ de 28/12/1901.

Em 1903, o regulamento do curso de parteira do mesmo Ministério de 28 de Outubro ( $D G, \mathrm{~N}^{\circ}{ }^{0248}$, de 4/11/1903), expressa o seguinte:

Art. $1 .^{\circ}$ - O curso de parteiras professado na UC e Escolas Médico-Cirúrgicas de Lisboa e Porto compreende dois anos.

$\S 10^{\circ}$ - A regência do Curso, no $10^{\circ}$ ano será confiado a um professor substituto da secção de cirúrgica, nomeado pelo Conselho Escolar, o 2. ${ }^{\circ}$ ano será regido pelo Professor de Obstetrícia, titular da cadeira.

$\S 2 .^{\circ}$ - Compete aos Conselhos escolares a elaboração dos programas a seguir na regência de cada ano, o $1 .^{\circ}$ ano deve restringir-se ao que for mais elementar (...) gravidez e partos normais, deixando para o segundo ano o estudo da distocia, os exercícios no manequim e a assistência clínica. Art. 2. ${ }^{\circ}$ - Nenhuma aluna do $1 .^{\circ}$ ano do curso de parteira será permitida a matrícula no $2 .^{\circ}$ ano sem ter prestado exame de passagem.

$\S$ Único - Este exame recairá sobre os rudimentos das matérias teóricas do curso e será tanto quanto possivel elementar e fácil.

Art. $3 .^{\circ}$ - As alunas parteiras que forem reprovadas em quatro exames de passagem não poderão matricular-se em novo curso de parteiras.

$\S$ Único - Nenhuma candidata ao curso de parteira deverá ser admitida sem apresentação de certidão negativa provando não estar nas condições deste artigo.

Art. $4 .^{\circ}$ - As alunas parteiras do $2 .^{\circ}$ ano não poderão renovar a sua matrícula depois de quatro exames. Para esta contagem somar-se-ão os de passagem com os de fim de curso. Explicita, exemplificando estas condições e no seu parágrafo único os casos de desistência que serão considerados para todos os efeitos como uma reprovação, exceptuando casos de força maior comprovada e apreciada pelo Conselho Escolar, sob informação do júri.

Art. $5^{\circ}$ - Nenhuma aluna será permitida a renovação da matrícula passados cinco anos a contar da primeira matrícula e exemplifica.

Art. 6. - Como norma será negada reinscrição no $1{ }^{\circ}$ ano depois de ausência superior a três anos e explicita como são obtidas estas contagens.

Art. 7. - Dois anos a contar da data de publicação do presente regulamento só serão admitidas à matricula no $1 .^{\circ}$ ano do curso de parteiras as candidatas que instruam os seus requerimentos com certidão de aprovação nas matérias que constituem o 2. ${ }^{\circ}$ grau de instrução primária, como estabelecido na lei de 24 de Dezembro de 1901.

Ficam revogadas as disposições em contrário (Secretário de Estado dos Negócios do Reino, 28 de Outubro de 2010).

A análise deste Regulamento do Curso de Parteiras revela uma preocupação de unificação de linguagem e de exigências entre as duas estruturas formativas: Faculdade de Medicina da UC e Escolas MédicoCirúrgicas de LisboaePorto. Otermoalunaéusado para os dois tipos de estrutura educativa, desaparecendo o termo de aspirante a parteira. O programa passa à responsabilidade do Conselho Escolar e não do Lente da disciplina. O $1 .^{\circ}$ ano é focado nos aspetos teóricos mais elementares e o segundo nos mais complexos, nas distocias, bem como na clínica. Surge o exame de passagem. A prescrição das normas de impedimento de repetição de matrícula de ano e de reinscrição no curso são minuciosamente descritas e exemplificadas (pela negativa).

As Escolas Médico-Cirúrgicas passam a Faculdades em 1911, daí que, por exemplo, em 1919 o Ministério da Instrução Pública, pelo Decreto N. o 6192/1919, aprova o Regulamento do Curso de Parteiras da Faculdade de Medicina de Lisboa (DG, N. ${ }^{\circ} 222$ de 30/10/1919).

Em Coimbra, na Obra de Protecção à Grávida e Defesa da Criança, foi criada por Bissaya Barreto, como Presidente da Junta Geral do Distrito, a Escola Normal Social (ENS), que incluía a formação de enfermeiras puericultoras visitadoras da Infância. A ENS começou a funcionar em 1937, embora só em 1939, pelo Decreto- 
Lei 30135 de 14 de Novembro, fosse oficializada e aprovados o plano geral de estudos e programas. Este assunto é tratado noutro documento.

Como apresentado na secção, anterior as «parteiras» curiosas operavam muito tempo após esta formação formal, e, não só nas aldeias do interior. Esta situação decorria da aceitabilidade e credibilidade granjeada, pela falta de recursos económicos que permitissem pagar os serviços duma parteira encartada/diplomada ou seria pela insuficiente cobertura das mesmas? Os resultados da pesquisa estatística de Carneiro (2007) apontam para esta última causa (quadros insertos nas p. 350, 351 e 352 ).

Correia (1937), apresenta, segundo um inquérito da Direcção Geral de Saúde de 1931, mais de um século após a formação de parteira pela Junta de Saúde Pública, um total de 703 parteiras, sendo 42 municipais e 661 diplomadas. A distribuição por distrito é muito assimétrica, por exemplo Bragança com zero parteiras em cada categoria, Guarda com um municipal e dois diplomadas, Coimbra zero Municipais e 15 diplomadas, em contrapartida Lisboa apresenta 363, sendo cinco parteiras municipais e 358 diplomadas e o Porto com a casa das municipais vazia e diplomadas

Tabela 2.

Legislação - Da Parteira a Enfermeira Puericultora
200?, com interrogação, segue-se-lhes Setúbal com 24, sendo cinco municipais e 19 diplomadas. Cruza estes dados com o número de nascimentos, que em Lisboa, dados de 1933, foi um total de 12803, com 11995 nados vivos e 808 nados mortos, ou seja menos de 3 partos por mês para cada parteira; no Porto 6258 , com 5903 nados vivos e 355 nados mortos, ou seja menos de três partos por mês para cada parteira (p.315). 0 número de partos por mês não lhes permitiria viver da profissão, visto que a grande maioria teriam «porta aberta», como se dizia. O autor, conclui:

O título serve à grande parte delas para lhe abrir portas para outras ocupações, desde o exercício ilegal da medicina à de abortadeiras, de que a sua classe nunca se defendeu com argumentos e provas sérias, aliás, tão fáceis de dar quando se quer. A falta de repressão de tais práticas é uma evidente cumplicidade. (p. 315, 316)

Daí, talvez, serem apelidadas de abortadeiras (Barreto, 2008) no Brasil e entre nós.

Com a criação do Instituto Maternal e suas Delegações, pelo DLn. ${ }^{0} 32651 / 43$ ( $D G$, n. ${ }^{\circ}$ 26, ISérie, de 2/02/1943) vamos entrar num outro paradigma formativo, objeto da secção seguinte e de outra publicação.

\begin{tabular}{|c|c|c|c|}
\hline $\begin{array}{l}\text { Ano } \\
\text { Legislação }\end{array}$ & Conteúdo & $\begin{array}{l}\text { Condições } \\
\text { admissão }\end{array}$ & $\begin{array}{l}\text { Título profis. } \\
\text { Entidade resp }\end{array}$ \\
\hline $\begin{array}{l}1836 \text { - Ministério Negócios do } \\
\text { Reino. Secretaria Estado (MNRSE) } \\
\text { Decreto de 5.12.1836, art. 85. } .^{\circ} \\
D G(295), 5.12 .1836\end{array}$ & $\begin{array}{l}\text { Aprova o Plano Geral de Estudos da Faculd. } \\
\text { Medicina (FM) da Univ. Coimbra, cria o } \\
\text { Curso de Arte Obstetrícia ( } 7 .^{\text {a Cadeira. }} \\
\text { Duração } 2 \text { anos. }\end{array}$ & Saber ler e escrever & $\begin{array}{l}\text { Parteira } \\
\text { Universidade de } \\
\text { Coimbra (UC) }\end{array}$ \\
\hline $\begin{array}{l}1836 \text { - MNR-SE } \\
\text { Decreto de } 29.12 .1936, \text { art. } \\
140^{\circ}-144^{\circ} . \\
D G .(3), 4.01 .1837\end{array}$ & $\begin{array}{l}\text { Determina que haverá em cada Escola } \\
\text { Medico-Cirúrgica um curso bienal, teórico } \\
\text { e prático, espec. destinado à formação de } \\
\text { parteiras. Duração } 2 \text { anos. }\end{array}$ & Saber ler e escrever & $\begin{array}{l}\text { Parteira } \\
\text { Carta, com proibições } \\
\text { Escolas Médico- } \\
\text { Cirúrgicas, Lisboa e } \\
\text { Porto }\end{array}$ \\
\hline $\begin{array}{l}1840 \text { - MNR-SE } \\
3 / 04 / 1840 \\
\text { Regulamento Escolas Médico- } \\
\text { Cirurgicas, Título II - Curso de } \\
\text { Parteiras, art. } 191^{\circ} \text { a } 205^{\circ} \text {. } \\
\text { DG (289), } 23.04 .1840\end{array}$ & $\begin{array}{l}\text { Mais minucioso que o decreto de } 1936, \\
\text { espec. os art }{ }^{\circ} 197 \text { exercício prático, } 198^{\circ} \text {, } \\
\text { as aspirantes serão entregues à Parteira } \\
\text { Superior..., } 199^{\circ} \text { sobre os registos, no } \\
\text { diário e livros, } 205^{\circ} \text { gratuitidade do Curso } \\
\text { (matrícula, exame, carta). } \\
\text { Duracão } 2 \text { anos }\end{array}$ & $\begin{array}{l}\text { Certidões: idade } \\
20 \text { A; Saber ler e } \\
\text { escrever. } \\
\text { Atestado de vida e } \\
\text { bons costumes }\end{array}$ & $\begin{array}{l}\text { Parteira } \\
\text { Carta c/proibições } \\
\text { Escolas Médico- } \\
\text { Cirúrgicas (EMC), } \\
\text { Lisboa e Porto }\end{array}$ \\
\hline
\end{tabular}


1870 - Ministério dos Negócios da Instrução Pública (MNIP)

$D G(156)$

16.07.1870

1901 - Presidência Conselho de Ministros, MNR, Direcção Geral IP Decreto de 24.12.1901, Reforma da UC, FM.

D.G. (294)

28.12.1901

1903 - MNR

Aprova Regulamento

$D G(248)$

4.11 .1903

1919 - Ministério da Instrução Pública

Decreto n. ${ }^{\circ} 6192$

$D G(222)$

31/10/1919

1943 Minnistério do Interior?

DL n. ${ }^{\circ} 32651 / 43$

$D G(26)$

2/02/1943
Estabelece o programa do exame de parteira. Poderão ser feitos na FMUC, EMC, à escolha das examinandas, Delegados de Saúde do Distrito, onde residam mais de um ano consecutivamente.

O curso obstetrício da FMUC. Dois anos de freq. da 12. ${ }^{\text {a }}$ cadeira (Obstetrícia,...), só serve p. este fim, $n$. pode ser levada em conta para o Curso Geral. As alunas são obrigadas a assistir a todos os partos que ocorrerem na respetiva enfermaria.

Regulamenta o curso de parteiras, FMUC e Escolas MC. Uniform. de linguagem e exigências. Exame passagem do $1 .^{\circ}$ para o 2. ${ }^{\circ}$ ano. Duração 2 anos.

Aprova o Regulamento do Curso de Parteiras da Faculdade de Medicina da Universidade de Lisboa

\section{Cria Instituto Maternal (IM), sua} organização e funções, o curso estagiários de Enf. Puericultoras, a funcionar no I M e nas suas Delegações. Regime de internato, especialmente feminino.
Certidões: idade

21A; Instrução

Primária; Não ter reprovado últimos

6 meses no curs...;

Atestados: Não padecer DIC, estar

vacin. ou ter tido

bexigas; bons costumes.

Instrução primária

Universidade de

Coimbra

Instrução primária

Prova que não

está incluída

nas condições

impeditivas ...

Parteira

Universidade de

Coimbra, Escolas MC

Lisboa, Porto

Parteira

CEG

“... terão ingresso enfermeiras que pretendam obter especialização".

\section{Enfermeira}

Puericultora

IM, Delegações

\section{Conclusão}

Da informação obtida emerge o perfil da «parteira» curiosa como uma mulher experiente, mãe, avó ou bisavó, pouco instruída, mas com sabedoria. Com uma postura digna e discreta, apresentação sóbria, cuidada, asseada, sendo respeitada e considerada, inclusive pelos médicos. Sempre disponível para acudir a uma mulher em trabalho de parto, a qualquer hora do dia, não se fazendo pagar pelos seus serviços. No parto e nos cuidados ao recém-nascido usava das medidas higiénicas básicas, para a época. De boa fama, no juízo popular, por isso operava na sua aldeia e redondezas. Não the são imputadas mortes de mães ou recémnascidos. Este perfil vai de encontro ao estudo de Barreto, tendo em atenção, os diferentes horizontes espaciais e temporais. Em suma, as «parteiras» neste estudo são vistas como mulheres de virtude.

A «parteira» mulher experiente, mãe e avó, madura ou mesmo idosa, dá lugar a uma parteira inexperiente no papel maternal, uma jovem que frequenta um curso formal, à qual é dada uma carta de parteira, com proibições, mas ao mesmo tempo esta carta pode ser obtida por meio de exame, sem ter frequentado um curso, sendo esta carta emitida com condições, além das proibições de não poder usar instrumentos cirúrgicos e outras.

Portanto, confirmam-se os pressupostos de partida. A primeira secção do estudo não recobre o território ao sul do distrito de Leiria, devido às nossas condições e recursos, continuá-lo é um desafio.

Seria interessante realizar estudos mais profundos, em universos mais abrangentes, descortinando as forças que levaram a que o parto natural se fosse institucionalizando, tornando-se tão frequentemente um parto patológico, um ato cirúrgico. Qual é a taxa de partos com atos cirúrgicos?

Em relação à legislação consultada, mais relevante, optámos por construir uma tabela resumo, segundo ordem cronológica, que a seguir se apresenta. 


\section{Referências Bibliográficas}

Barreto, M. R. (2007). A ciência do parto nos manuais portugueses de obstetrícia. Género: Revista do Núcleo Transdisciplinar de Estudos de Gênero, 7(2), 217-234.

Barreto, M. R. (2008). Assistência ao nascimento na Bahia oitocentista. História, Ciência, Saúde - Manguinhos, 15(4), 901-925.

Bessa, J. S. (1986). Intervenção na comemoração dos 20 anos de actividade da Maternidade Bissaya Barreto. Revista da Fundação Bissaya Barreto, 2, 31-42).

Barreto, B. (1946). Subsídios para a História (I) (3 ed.). Coimbra, Portugal: Gráfica de Coimbra.

Collière, M.-F. (1989). Promover a vida: Da prática das mulheres de virtude aos cuidados de Enfermagem. Lisboa, Portugal: Edição do Sindicato dos Enfermeiros Portugueses.

Carneiro, M. N. (2005). A nova cultura científica na obstetrícia e seus efeitos profissionais (séc. XIX). Revista da Faculdade de Letras. História, 3(6), 69-98.
Carneiro, M. N. (2007). Ordenamento sanitário, profissões de saúde e cursos de parteiras no Século XIX. Revista da Faculdade de Letras, História, 3(8), 317-354.

Carrington, R. B., Gomes, D., \& Oliveira, L. C. (1969). Terapêutica do tétano. Separata da Revista Coimbra Médica, 16(7), 707717.

Correia, F. S. (1937). Portugal sanitário (Tese de doutoramento, Universidade de Coimbra). Lisboa, Portugal: Tipografia da Empresa do Anuário Comercial.

Mazarém, J. R. (1838). Recopilação da arte dos partos, ou quadro elementar obstetrício para instrução das aspirantes que frequentam o curso de partos. Lisboa, Portugal: Imp. de J. M. R. e Castro.

Raposo, L. (1931). Obra de protecção à grávida e defesa da criança: Suas origens e seus fins. Coimbra, Portugal: Junta Geral do Distrito de Coimbra.

Valente, I. (2013). Percursos, vivencias e novos caminhos. Coimbra, Portugal: Minerva. 
